\title{
Supporting Information: Development of Vickers hardness prediction models via microstructural analysis and machine learning
}

\author{
Sucheta Swetlana · Nikhil Khatavkar · Abhishek Kumar Singh
}

Received: date / Accepted: date

\section{Data Collection}

Table S1 includes the references of the experimental reports used as input data for development of ML model.

Table S1: References for the microstructures and experimental data used in this work.

\begin{tabular}{lll}
\hline Sl.No. & System & Reference \\
\hline 1 & NiCrAlNb & {$[1]$} \\
2 & CoNiAlTi & {$[2]$} \\
3 & CoNiAlWTi & {$[2]$} \\
4 & CoAlWTa & {$[3]$} \\
5 & CoAlWMo & {$[3]$} \\
6 & CoAlWCrNi & {$[4]$} \\
7 & CoAlWCr & {$[4]$} \\
8 & CoAlW & {$[4]$} \\
9 & CoAlWMo & {$[4]$} \\
10 & CoAlWV & {$[4]$} \\
11 & CoAlWTi & {$[4]$} \\
12 & CoAlWTa & {$[4]$} \\
13 & CoAlWNi & {$[4]$} \\
14 & CoAlWNiV & {$[4]$} \\
15 & CoAlWSi & {$[4]$} \\
16 & CoAlWFe & {$[4]$} \\
17 & NiAlTiV & {$[5]$} \\
18 & NiAlNbV & {$[6]$} \\
19 & NiCrAlCoWTaTiMoC & {$[7]$} \\
20 & NiCrCoMoWTiAlCBZr & {$[8]$} \\
21 & NiCrCoMoAlTiTaZrCB & {$[9]$} \\
22 & NiCrCoTiAlMoHfW & {$[10]$} \\
23 & NiFeCrMoTiNbAlCB & {$[11]$} \\
24 & NiCrCoMoWTiAlCBZr & {$[12]$} \\
25 & NiTiAlNbCrCoFeMoWC & {$[13]$} \\
26 & CoNiTiCrMoAlW & {$[14]$} \\
27 & NiCrMoFeWMnSiCB & {$[15]$} \\
28 & NiCrMoTiAlNbCo & {$[16]$} \\
29 & CoAlWTaTiCrNiHfC & {$[17]$}
\end{tabular}

Sucheta Swetlana

Materials Research Centre, Indian Institute of Science, Bangalore, India, 560012 E-mail: suchetas@iisc.ac.in

Nikhil Khatavkar

Materials Research Centre, Indian Institute of Science, Bangalore, India, 560012 E-mail: nikhilk@iisc.ac.in

Abhishek Kumar Singh

Materials Research Centre, Indian Institute of Science, Bangalore, India, 560012 E-mail: abhishek@iisc.ac.in 


\begin{tabular}{lll}
30 & NiCrFeTiAlTaNb & {$[18]$} \\
31 & NiCCrCoMoWTaTiAlBHf & {$[19]$} \\
32 & NiCoCrMoHfTaAlWReCZrB & {$[20]$} \\
33 & NiCoCrAlTiZrNbMoWTaHfBC & {$[21]$} \\
34 & NiCoCrMoFeSiMnCAlTiCuPBSZr & {$[10]$} \\
\hline
\end{tabular}

\section{Structural features obtained using Image processing}

The Table $\mathrm{S} 2$ below describes the geometrical features which are evaluated using various image processing filters and algorithms. These features are considered as structural descriptors.

Table S2: Structural descriptors

\begin{tabular}{|c|c|c|c|}
\hline Sl. & Features & Description & Notation used \\
\hline 1 & Volume (area) fraction & $\begin{array}{l}\text { The ratio of number of areal pixels in white } \\
\text { section }\left(\gamma^{\prime} \text { phase }\right) \text { to the total number of pix- } \\
\text { els }\left(\gamma+\gamma^{\prime} \text { phase }\right) \text { in the binarised image. }\end{array}$ & $\mathrm{VF}$ \\
\hline 2 & Boundary fraction & $\begin{array}{l}\text { The ratio of number of boundary pixels in the } \\
\text { white section }\left(\gamma^{\prime} \text { phase) to the total number of }\right. \\
\text { pixels }\left(\gamma+\gamma^{\prime} \text { phase }\right) \text { in the canny image. }\end{array}$ & $\mathrm{BF}$ \\
\hline 3 & Effective area & $\begin{array}{l}\text { The number of pixels contained in white sec- } \\
\text { tion }\left(\gamma^{\prime} \text { phase) calculated over the number }\right. \\
\text { density of } \gamma^{\prime} \text { phase. }\end{array}$ & $A_{e f f}$ \\
\hline 4 & Effective perimeter & $\begin{array}{l}\text { The number of pixels on the border of white } \\
\text { section }\left(\gamma^{\prime} \text { phase }\right) \text { calculated over the number } \\
\text { density of } \gamma^{\prime} \text { phase. }\end{array}$ & $P_{e f f}$ \\
\hline 5 & Effective radius & $\begin{array}{l}\text { The average radius of white section }\left(\gamma^{\prime}\right. \\
\text { phase) calculated over the number density of } \\
\gamma^{\prime} \text { phase. }\end{array}$ & $R_{e f f}$ \\
\hline 6 & $\begin{array}{l}\text { Shape factor or circu- } \\
\text { larity }\end{array}$ & $\begin{array}{l}\text { The compactness of the area in the white sec- } \\
\text { tion }\left(\gamma^{\prime} \text { phase) calculated over the number }\right. \\
\text { density of } \gamma^{\prime} \text { phase. }\end{array}$ & $\mathrm{SF}$ \\
\hline 7 & Aspect ratio & $\begin{array}{l}\text { The ratio of minor to major axis of the min- } \\
\text { imum enclosing rectangle that surrounds the } \\
\text { white section. }\end{array}$ & AR \\
\hline 8 & Density of grains & $\begin{array}{l}\text { The number of grains }\left(\gamma^{\prime} \text { phase }\right) \text { included in } \\
\text { the image. }\end{array}$ & $N_{o b j}$ \\
\hline
\end{tabular}

\section{List of elemental features}

The table below illustrates the composition-weighted averaged elemental features, which are considered as descriptors.

Table S3: Elemental descriptors

\begin{tabular}{lll}
\hline Sl. & Elemental features & Notation used \\
\hline 1 & Melting point & $\mathrm{T}_{M}^{\text {mean }}$ \\
2 & Boiling point & $\mathrm{T}_{B}^{\text {mean }}$ \\
3 & Specific heat & $\mathrm{C}_{V}^{\text {mean }}$ \\
4 & Pauli electronegativity & $\mathrm{E}_{p}^{\text {mean }}$ \\
5 & Electron affinity & $\mathrm{E}_{a}^{\text {mean }}$ \\
6 & Valency & $\mathrm{V}^{\text {mean }}$ \\
7 & First ionisation energy & $\mathrm{E}_{1}^{\text {mean }}$ \\
8 & Covalent radius & $\mathrm{r}_{\text {cou }}^{\text {mean }}$ \\
9 & Density & $\rho^{\text {mean }}$ \\
10 & Bulk Modulus & $\mathrm{B}^{\text {mean }}$ \\
11 & Thermal Conductivity & $\kappa^{\text {mean }}$ \\
\hline
\end{tabular}




\section{Standardization}

Figure S1 shows the standardization of features by subtracting the mean and dividing by the standard deviation for the training data.

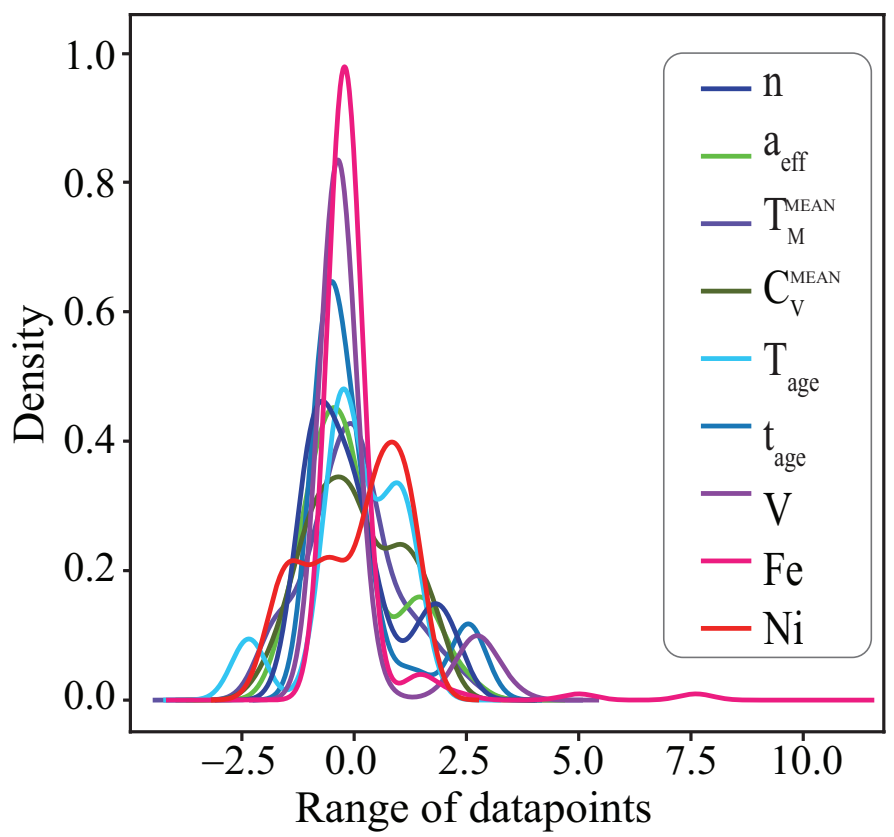

Fig. S1 Standardization of data for preprocessing of ML model

\section{Machine learning models}

Fig S2 shows the performance of different ML models on the best feature set (feature set-III). The GPR model outperforms giving the highest $R^{2}$ of $0.99 / 0.98$ and lower rmse of $0.13 / 0.15$ for train/test data. 


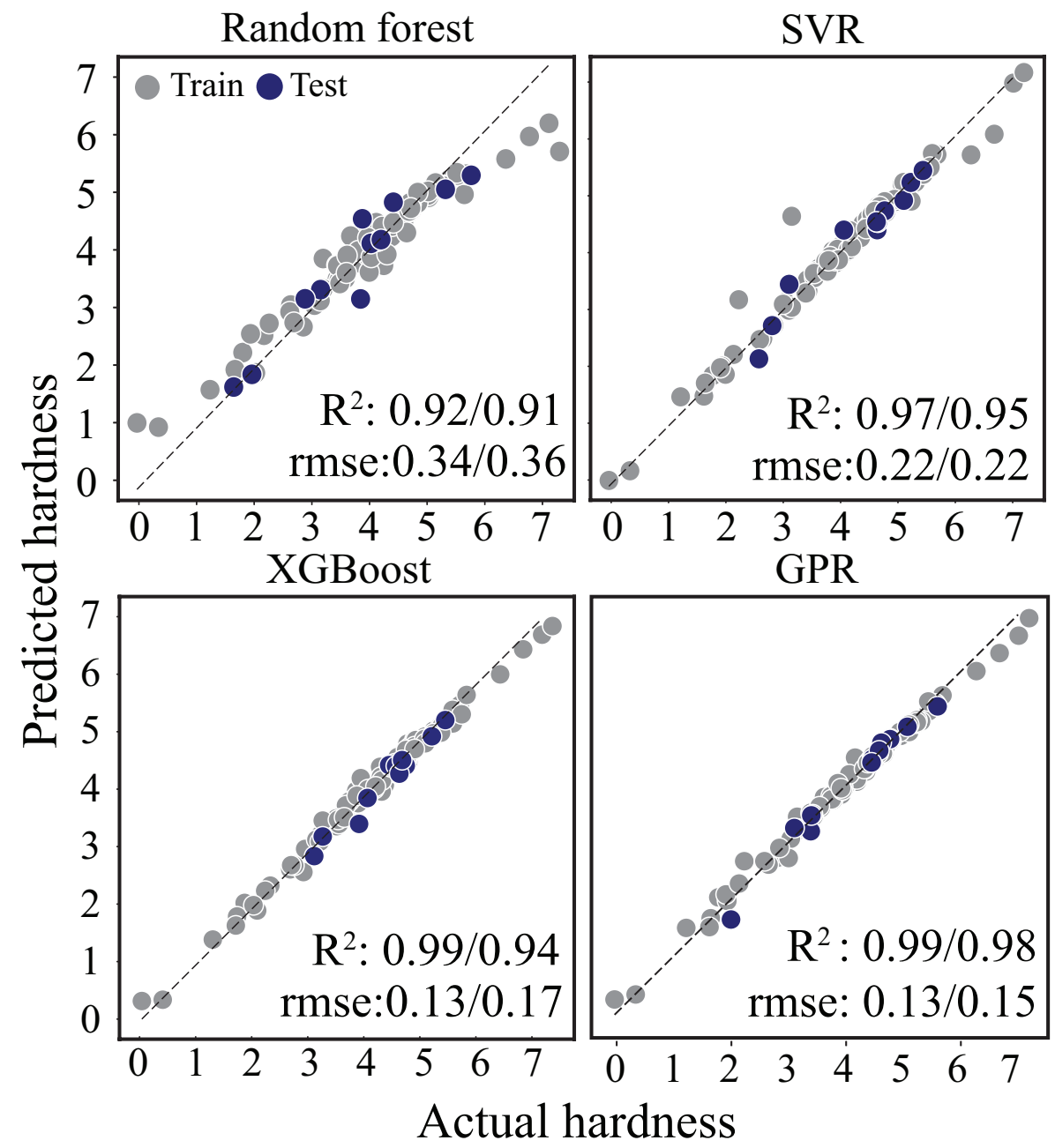

Fig. S2 Performance of different models on feature set-III

\section{Learning Curve}

Figure S2 shows the learning curve for the developed model with feature set-III. As a function of increasing training data, the train and test $R^{2}$ and rmse converge around 0.98 and 0.15 , respectively, showing no overfitting for 90 percent of training data.
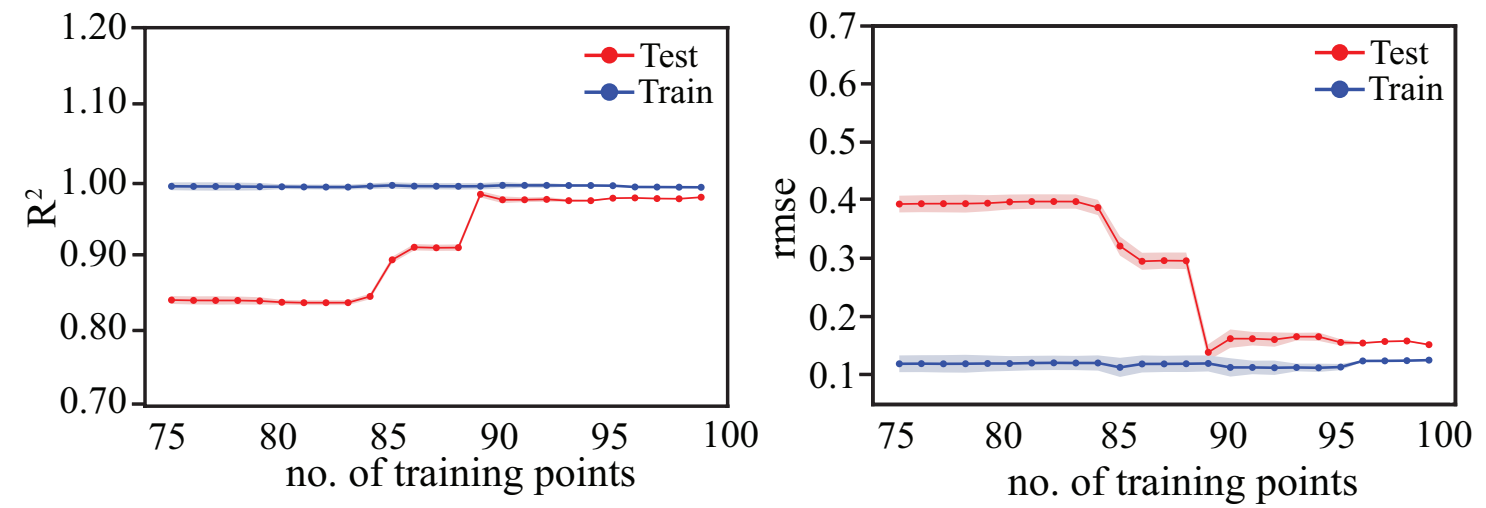

Fig. S3 Learning curve for different training datapoints for Feature set-III 


\section{Validation of ML model}

For the validation of our best model, some random SEM microstructures of Co- and Ni-based superalloys [22, 23,24] are collected and the best GPR model is employed to predict Vickers hardness. The table below shows the predictive capability of our model on unseen data. Further, from the residual plot shown in Fig S4, it can be ascertained that the prediction error is minimal. Thus, our developed model can be utilised to predict Vickers hardness for any unseen data.

Table S4: Validation of GPR model

\begin{tabular}{lll}
\hline SI. & Actual (Experimental) hardness & Predicted (ML) hardness \\
\hline 1 & 3.84 & 5.05 \\
2 & 4.59 & 5.17 \\
3 & 4.16 & 2.92 \\
4 & 4.13 & 4.09 \\
5 & 3.91 & 3.46 \\
6 & 3.92 & 3.14 \\
7 & 3.97 & 2.79 \\
8 & 3.61 & 2.88 \\
\hline
\end{tabular}

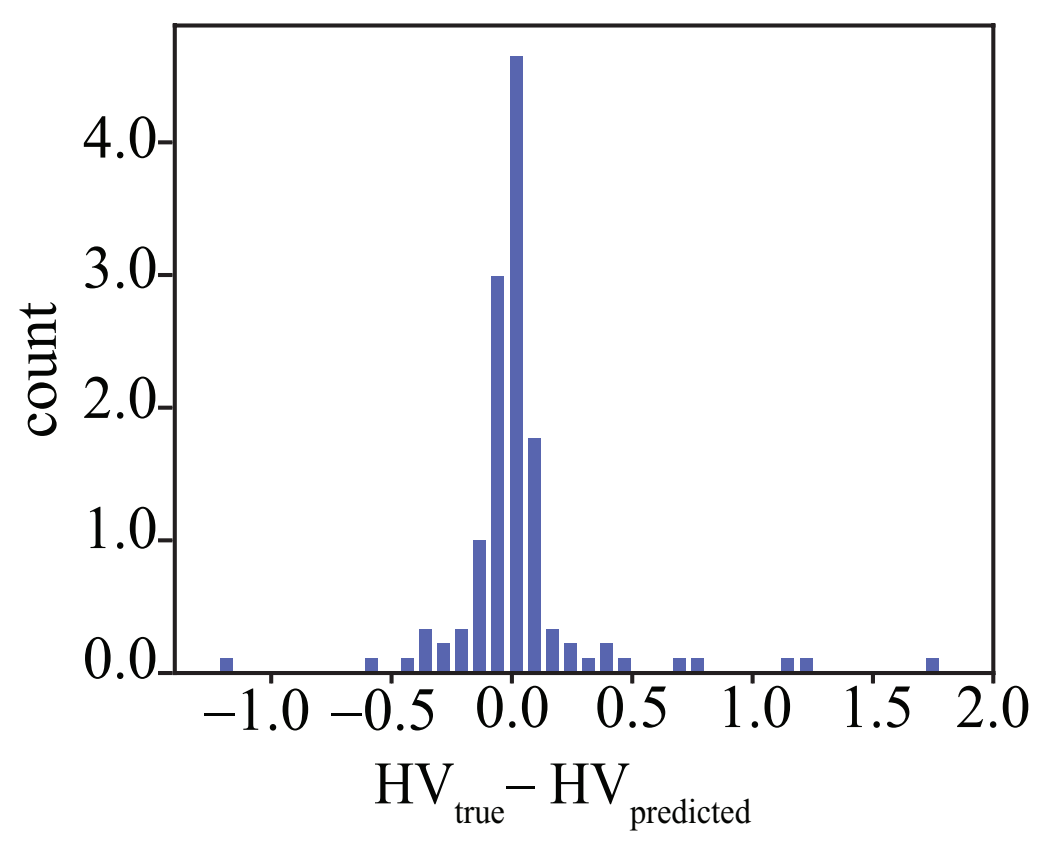

Fig. S4 Residual plot for validation of unseen data for the prediction of Vickers hardness. 


\section{References}

1. P.M. Mignanelli, N.G. Jones, M. Hardy, H.J. Stone, Materials Science and Engineering: A 612, 179 (2014)

2. P.J. Bocchini, C.K. Sudbrack, D.J. Sauza, R.D. Noebe, D.N. Seidman, D.C. Dunand, Materials Science and Engineering: A 700, 481 (2017)

3. J. Sato, T. Omori, K. Oikawa, I. Ohnuma, R. Kainuma, K. Ishida, Science 312(5770), 90 (2006)

4. H.Y. Yan, V. Vorontsov, D. Dye, Intermetallics 48, 44 (2014)

5. Y. Nunomura, Y. Kaneno, H. Tsuda, T. Takasugi, Acta materialia 54(3), 851 (2006)

6. K. Kawahara, Y. Kaneno, A. Kakitsuji, T. Takasugi, Intermetallics 17(11), 938 (2009)

7. C. Barbosa, J. Nascimento, I. Caminha, I. Abud, Engineering Failure Analysis 12(3), 348 (2005)

8. T. Osada, N. Nagashima, Y. Gu, Y. Yuan, T. Yokokawa, H. Harada, Scripta Materialia 64(9), 892 (2011)

9. R. Mitchell, M. Preuss, S. Tin, M. Hardy, Materials Science and Engineering: A 473(1-2), 158 (2008)

10. M. Göken, M. Kempf, Acta Materialia 47(3), 1043 (1999)

11. Z. Zhong, Y. Gu, Y. Yuan, Z. Shi, Materials Letters 109, 38 (2013)

12. T. Osada, Y. Gu, N. Nagashima, Y. Yuan, T. Yokokawa, H. Harada, Acta Materialia 61(5), 1820 (2013)

13. G.A. Zickler, R. Schnitzer, R. Radis, R. Hochfellner, R. Schweins, M. Stockinger, H. Leitner, Materials Science and Engineering: A 523(1-2), 295 (2009)

14. C. Cui, D. Ping, Y. Gu, H. Harada, Materials transactions 47(8), 2099 (2006)

15. X. Li, J. Bai, P. Liu, Y. Zhu, X. Xie, Q. Zhan, Journal of Alloys and Compounds 559, 81 (2013)

16. H. Li, X. Song, Y. Wang, G. Chen, Rare Metals 29(2), 204 (2010)

17. Y. Zhang, H. Fu, X. Zhou, Y. Zhang, J. Xie, Materials Science and Engineering: A 737, 265 (2018)

18. A. Picasso, A. Somoza, A. Tolley, Journal of Alloys and Compounds 479(1-2), 129 (2009)

19. H. Peng, Y. Shi, S. Gong, H. Guo, B. Chen, Materials \& Design 159, 155 (2018)

20. L. Murr, E. Martinez, X. Pan, S. Gaytan, J. Castro, C. Terrazas, F. Medina, R. Wicker, D. Abbott, Acta Materialia 61(11), 4289 (2013)

21. H. Kim, S. Chun, X. Yao, Y. Fang, J. Choi, Journal of Materials Science 32(18), 4917 (1997)

22. H. Wu, X. Zhuang, Y. Nie, Y. Li, L. Jiang, Materials Science and Engineering: A 754, 29 (2019)

23. C. Che, S. Yang, M. Wei, L. Zhang, Q. Li, J. Gao, Y. Du, Journal of Mining and Metallurgy, Section B: Metallurgy 53(3), 303 (2017)

24. F.L.R. Tirado, S. Taylor, D.C. Dunand, Acta Materialia 172, 44 (2019) 